\section{Can we simply infer mitochondrial function from PCr resynthesis after exercise in skeletal muscle?}

doi:10.1038/pr.2012.67

To the Editor: We have read with much interest the paper recently published by Wells et al. regarding the abnormalities of muscle metabolism in adolescents with cystic fibrosis and primary ciliary dyskinesia (1). Although the results of this investigation are of potential interest, we are concerned about the utilization of the time constant of phosphocreatine recovery $(\tau \mathrm{PCr})$ as a simple index of mitochondrial function and the corresponding conclusions regarding the impact of cystic fibrosis on muscle metabolism during exercise. The real issue is to clearly determine whether one can infer mitochondrial function on the basis of measurements of $\tau$ PCr.

During recovery from exercise, phosphocreatine is resynthesized purely as a consequence of oxidative ATP synthesis (2) and measurements of the time constant of $\tau \mathrm{PCr}$ have been used to characterize mitochondrial function in a variety of conditions (3). However, several studies have clearly demonstrated that cytosolic $\mathrm{pH}$ has a strong influence (3). It is well acknowledged that $\tau \mathrm{PCr}$ is positively related to the extent of intracellular acidosis and $\mathrm{PCr}$ consumed (3). In other words, a significant intracellular acidosis and a large PCr consumption in exercising muscle would be associated with a slower PCr resynthesis (3). In the Wells et al. (1) study, cytosolic $\mathrm{pH}$ was reduced to a smaller extent after highintensity exercise in adolescents with cystic fibrosis as compared with controls. Therefore, the magnitude of changes in muscle oxidative capacity on the simple basis of $\tau \mathrm{PCr}$ measurements could have been underestimated in patients with cystic fibrosis. Of note, several kinetic parameters are usually used to describe $\mathrm{PCr}$ changes during exercise-to-recovery transition, including $\tau \mathrm{PCr}$, the initial rate of $\mathrm{PCr}$ recovery, and the maximum aerobic capacity (4). These three parameters characterizing PCr resynthesis are correlated to oxidative capacity. However, in contrast to $\tau \mathrm{PCr}$, the initial rate of $\mathrm{PCr}$ recovery, and the maximum aerobic capacity are insensitive to exercise intensity and end-of-exercise metabolic conditions (3). On that basis, the initial rate of $\mathrm{PCr}$ recovery and the maximum aerobic capacity should be considered as additional indexes to compare the post-exercise $\mathrm{PCr}$ recovery rate and mitochondrial oxidative capacity across different populations when end-of-exercise $\mathrm{pH}$ and $\mathrm{PCr}$ concentration values are different or not taken into account. This was the case in some previously published studies that investigated in vivo mitochondrial function from childhood to young and/or late adulthood $(5,6)$. In contrast, this was not the case in other studies that investigated age-related changes in mitochondrial oxidative capacity from childhood to adulthood (7) and examined the association between mitochondrial alterations and insulin sensitivity in overweight and normal-weight children (8).

Overall, it is of utmost importance to keep in mind that one cannot simply infer mitochondrial function on the basis of measurements of the rate constant of $\mathrm{PCr}$ resynthesis given that end-of-exercise conditions have been shown to exert a strong influence. Future studies should pay attention to these methodological inaccuracies, which might hedge data interpretation and confound the corresponding conclusions.

Editor's note: Dr Wells was offered the opportunity to respond to this letter but declined to submit a reply.

\section{Sébastien Ratel', Vincent Martin', Anne Tonson', Patrick J. Cozzone ${ }^{2}$ and David Bendahan ${ }^{2}$}

${ }^{1}$ Clermont Université, Université Blaise Pascal, EA 3533, Laboratoire des Adaptations Métaboliques à l'Exercice en Conditions Physiologiques et Pathologiques (AME2P), Aubière, France; ${ }^{2}$ Centre de Résonance Magnétique Biologique et Médicale (CRMBM), Faculté de Médecine de Marseille, Université de la Méditerranée, Marseille, France.

Correspondence: Sébastien Ratel

(Sebastien.RATEL@univ-bpclermont.fr)

\section{REFERENCES}

1. Wells GD, Wilkes DL, Schneiderman JE, et al. Skeletal muscle metabolism in cystic fibrosis and primary ciliary dyskinesia. Pediatr Res 2011;69:40-5.

2. Quistorff B, Johansen L, Sahlin K. Absence of phosphocreatine resynthesis in human calf muscle during ischaemic recovery. Biochem J 1993;291 (Pt 3):681-6.

3. Roussel M, Bendahan D, Mattei JP, Le Fur Y, Cozzone PJ. 31P magnetic resonance spectroscopy study of phosphocreatine recovery kinetics in skeletal muscle: the issue of intersubject variability. Biochim Biophys Acta 2000;1457:18-26.

4. Tonson A, Ratel S, Le Fur Y, Vilmen C, Cozzone PJ, Bendahan D. Muscle energetics changes throughout maturation: a quantitative 31P-MRS analysis. J Appl Physiol 2010;109:1769-78.

5. Barker AR, Welsman JR, Fulford J, Welford D, Armstrong N. Muscle phosphocreatine kinetics in children and adults at the onset and offset of moderate-intensity exercise. J Appl Physiol 2008;105:446-56.

6. Taylor DJ, Kemp GJ, Thompson CH, Radda GK. Ageing: effects on oxidative function of skeletal muscle in vivo. Mol Cell Biochem 1997;174:321-4.

7. Fleischman A, Makimura H, Stanley TL, et al. Skeletal muscle phosphocreatine recovery after submaximal exercise in children and young and middle-aged adults. J Clin Endocrinol Metab 2010;95:E69-74.

8. Fleischman A, Kron M, Systrom DM, Hrovat M, Grinspoon SK. Mitochondrial function and insulin resistance in overweight and normal-weight children. J Clin Endocrinol Metab 2009;94:4923-30. 